\title{
InterviewStreamliner, a minimalist, free, open source, relational approach to computer-assisted qualitative data analysis software
}

\author{
Hans Pruijt \\ Erasmus Universiteit Rotterdam \\ pruijt@fsw.eur.nl \\ Preprint version \\ Accepted for publication in Social Science Computer Review, Volume 28, No. 2, Summer \\ 2010 \\ abstract: \\ InterviewStreamliner is a free, open source, minimalist alternative to complex computer- \\ assisted qualitative data analysis packages. It builds on the flexibility of relational database \\ management technology.
}

keywords: computer-assisted qualitative data analysis, CAQDAS, qualitative research

The currently fashionable computer-assisted qualitative data analysis software (CAQDAS) packages are complex, which results in considerable learning curves and costs. Nevertheless, their core functionality remains simple: coding, retrieving and recoding text fragments (Lewins 2007; 2009). This contradiction spurred the development of InterviewStreamliner. The goal was to create a free CAQDAS package that is as easy to use as possible and leverages existing skills. Also, an important wish was to eliminate the need for software installation, a hurdle to deployment in a centrally controlled computing environment. The strategy was to capitalize on the widespread availability of relational database management systems, such as MS Access. Relational database management systems are geared to the world of parts numbers and customer names, not so much to the textual data that is characteristic of qualitative research (Pruijt 1991; Schipper 1991). In this area, there has been little improvement over time. Additional programming is still required to obtain the desired functionality. InterviewStreamliner provides this. It was implemented as a MS Access application. On computers that already have MS Office Professional installed, no further software installation is necessary. Users who do not have MS Access can instead run InterviewStreamliner with the Access 2007 runtime, which is freely downloadable from the Microsoft website.

One design decision was to leave as much as practical to the word processing and operating system software that the users are already familiar with. Thus, initial coding is done in the word processor. This involves creating (a) text file(s) in this format: 


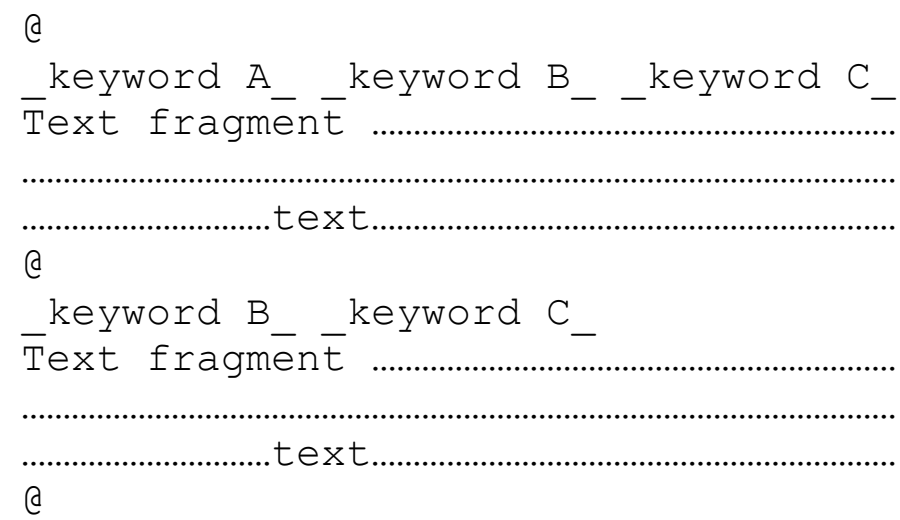

The @-sign separates fragments or scenes, keywords are marked by enclosing them in underscores (_).

InterviewStreamliner's minimalism is apparent when it starts (figure 1).

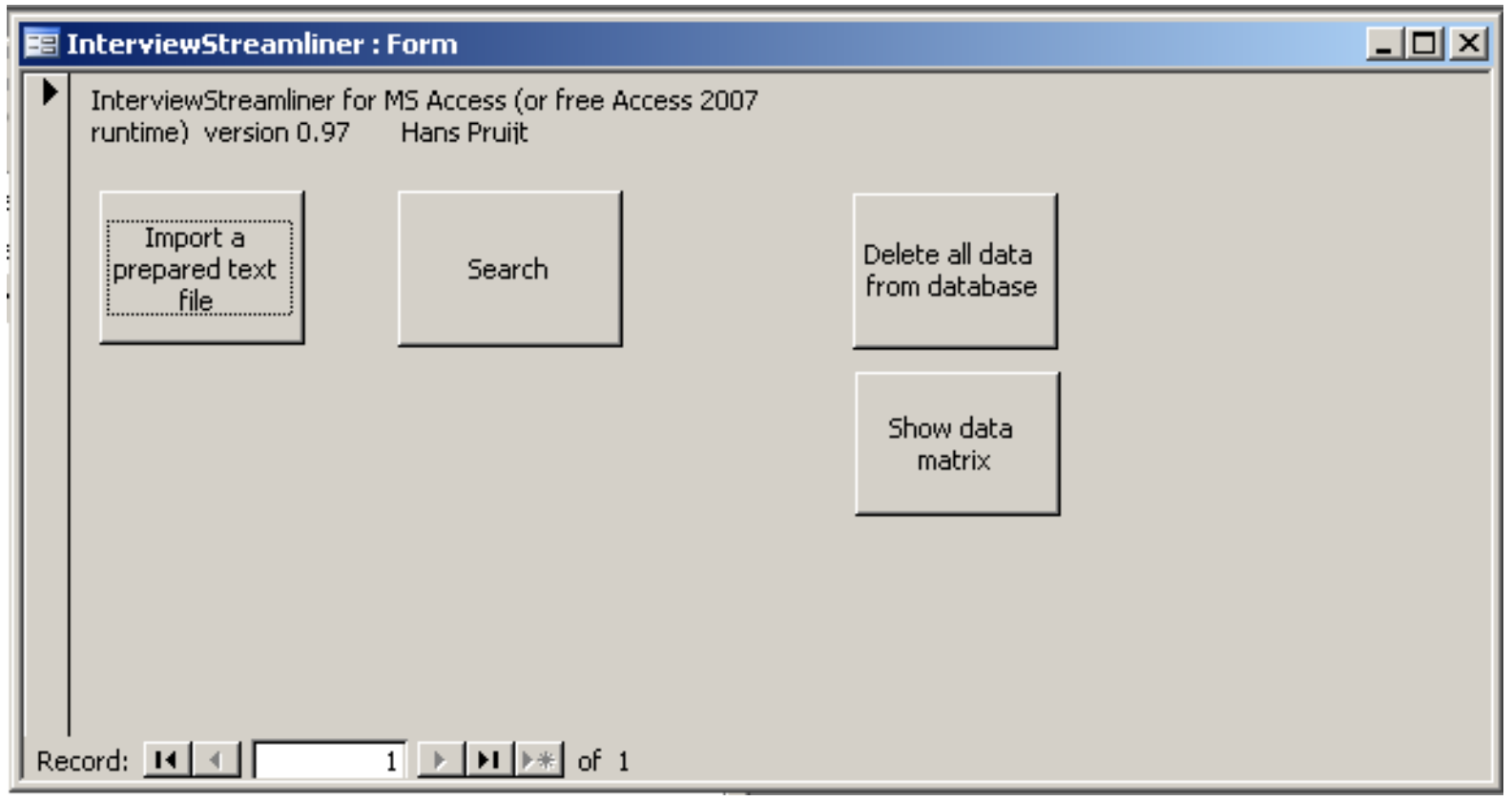

\section{Figure 1 Startup form}

After importing one or more input files, fragments can be retrieved (figures 2 and 3). 


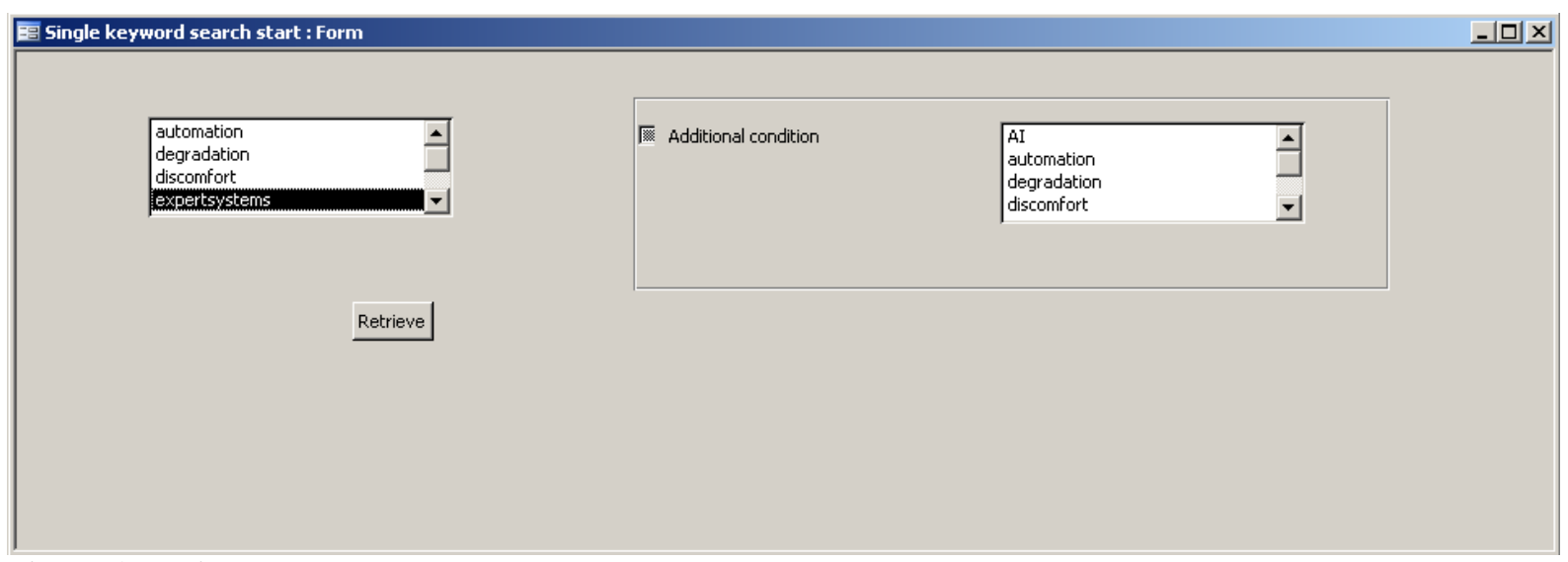

Figure 2 retrieval

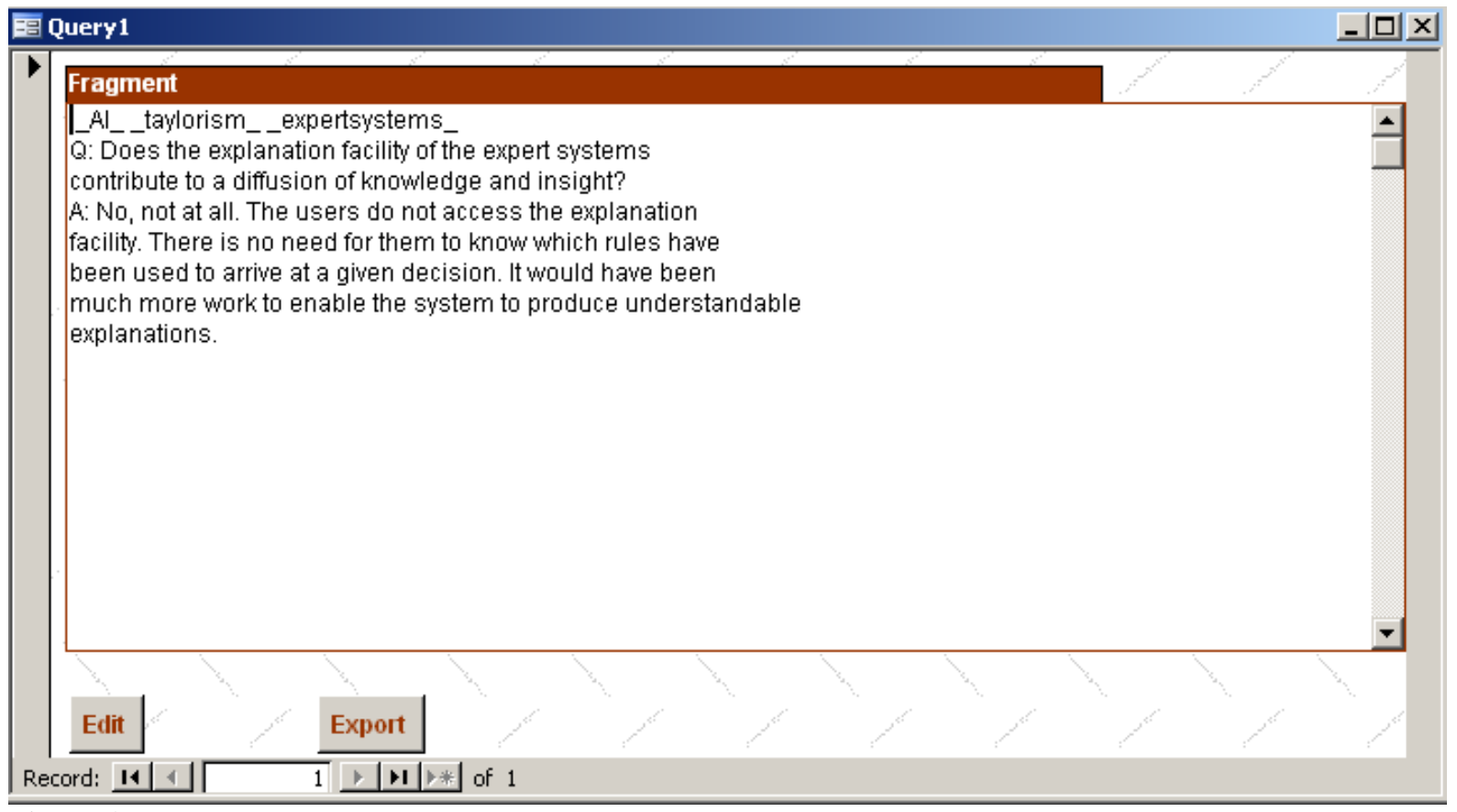

Figure 3 output

From here, the user can edit the record or export the retrieved records to an external file. Recoding takes place in the editing form (figure 4). 


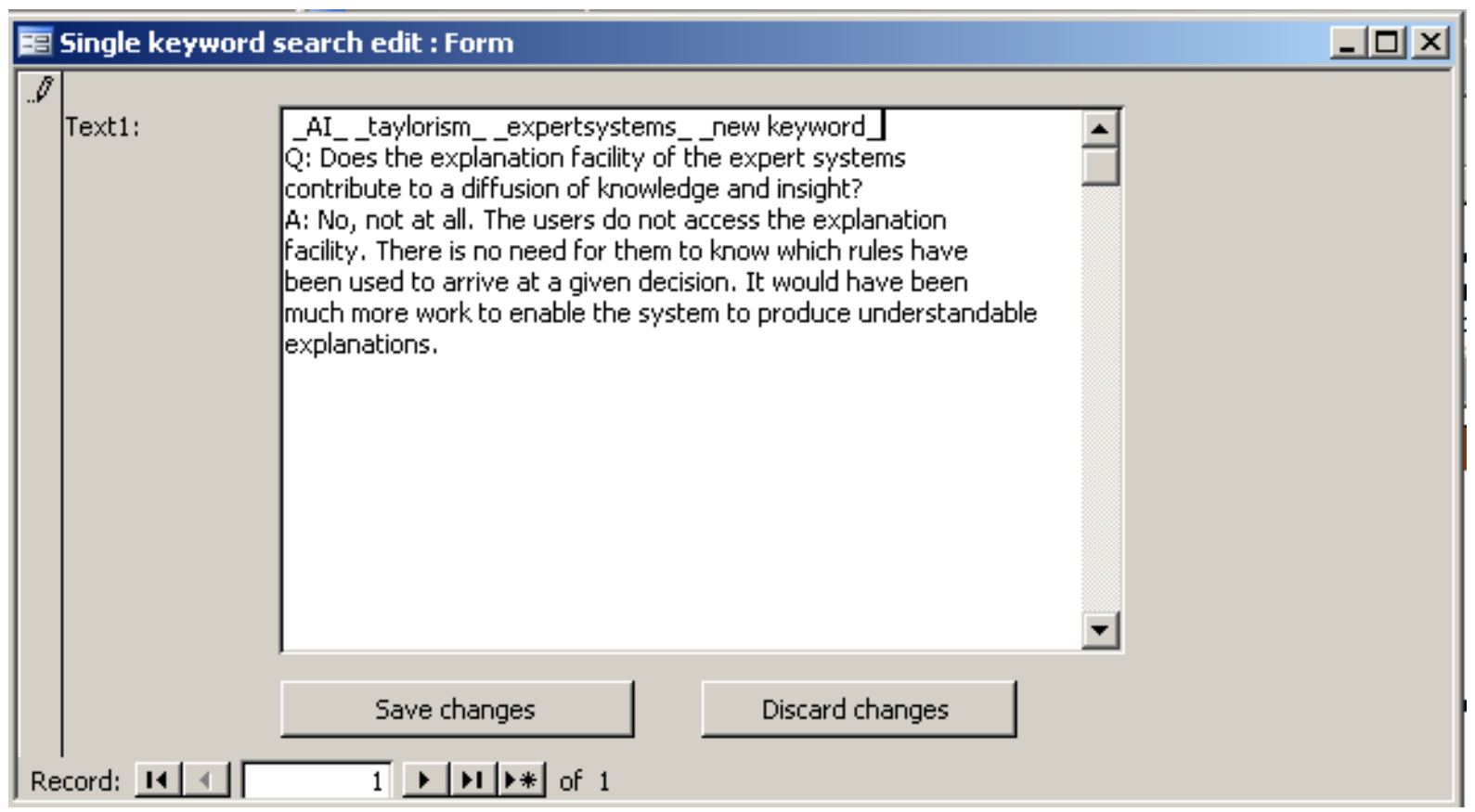

Figure 4 editing

Users who find it useful to link retrieved fragments back to their original context can, when preparing the input file(s), insert a special, unique label at the top of each interview (or any other type of section). When building the database, InterviewStreamliner copies this label to each fragment of the interview. The optional label must be preceded by a $\sim$ and be in an otherwise blank line. See the example below.

Suppose that the file consists of two interview transcriptions. The first interview is labeled as: " systems analyst 1". The second interview is labeled as " systems analyst $2 "$ ". After processing the line " $\sim$ systems analyst 1", InterviewStreamliner will copy this label to each subsequent fragment, until it encounters the line " $\sim$ systems analyst 2". From that point onwards, each fragment automatically gets labeled " $\sim$ systems-analyst 2 ".

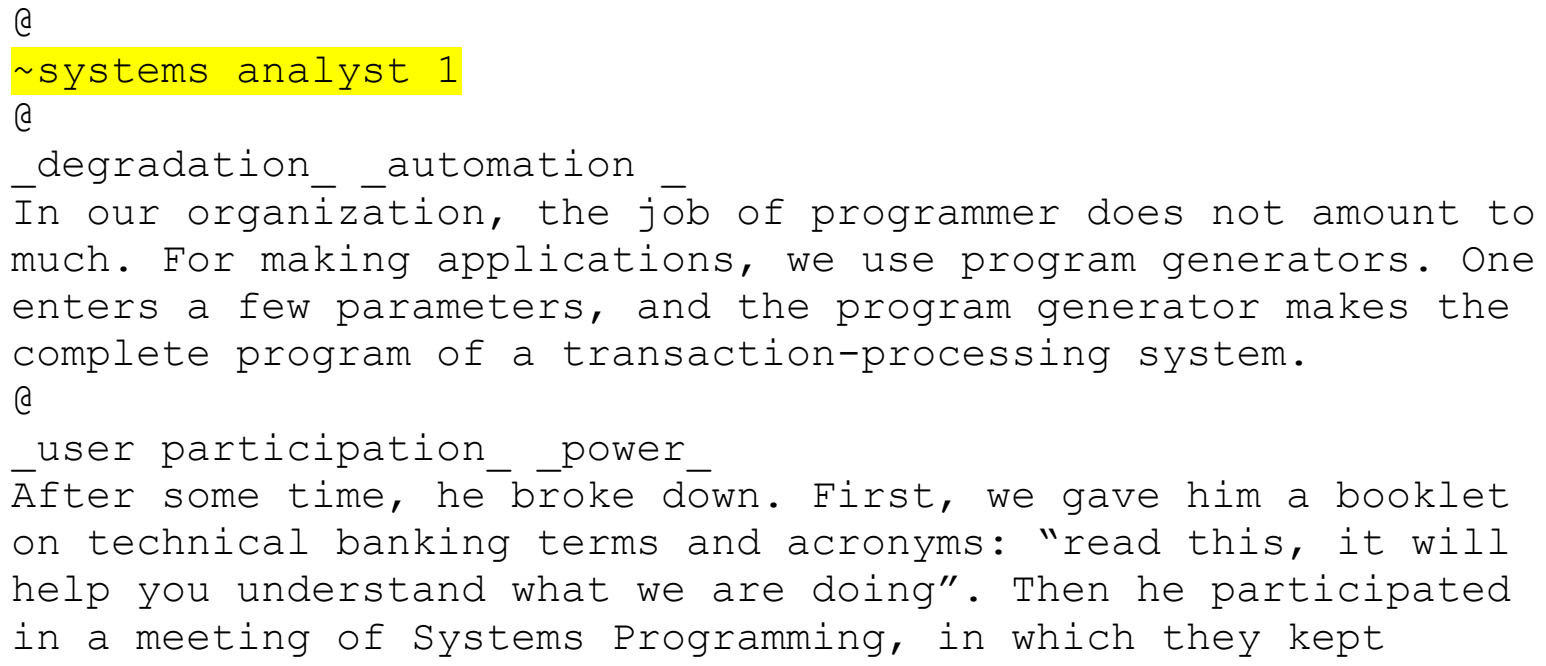


introducing words that were completely new to him. Then we gave him a glossary of specific terms and abbreviations for the project. This was followed by yet another meeting in which he again found himself bombarded with completely new

terminology. The final blow was when I handed him a report on "overnight processing in local areas". He asked to be sent back to his boss. In retrospect, this was the most frustrating thing that you can do to somebody.

c

power

$\bar{N}$ t on $\bar{y}$ are we sitting in an ivory tower, but we also laid a minefield around us. This happened when we stopped asking the users about how they did their work and, instead, began to determine the work flow ourselves. When I had completed a manual, somebody said: couldn't you relate this to how the work used to be done? I said no, because it was not relevant. Plus, I did not even know exactly how the work process had been before.

a systems analyst 2 a

degradation

$\bar{Q}$ I we look at jobs that are being hollowed out, would it be right to conclude that especially the job of systems analyst is hollowed out?

A Yes. For instance, in the market group, someone, on the shop floor level, gets as assignment to keep in touch with IT. Such users typically know a lot about IT. They may, for example, specify that the color of cars should be recorded, and also say how it is to be done; "I want it in this table and not in that one." The systems analyst is wedged between the user and the programmer. In fact, he is more like a systems

administrator.

c

user participation

$\bar{I}$ practice, we ten $\bar{d}$ to be too eager to please the users. We built a system based on a regional division scheme that users suggested, although management had already decided that is was going to be changed.

c

Testing in the computer lab confirmed that students can quickly learn to use InterviewStreamliner. Problems that came up related to general computing skills; brushing up those skills has value way beyond the context of qualitative analysis. What should help motivation is that using InterviewStreamliner involves standard software found in countless workplaces. 
The use of a relational database management system as a basis provides additional benefits. One benefit is that accessing the data from other programs is easy. And, when using not the runtime version but the full version of Access, all of its flexible database management functionality is available for creative use. Figure 5 shows the database structure.

Table Data

\begin{tabular}{|c|c|c|c|}
\hline Fragment & FragmentID & Case & \\
\hline \multicolumn{4}{|c|}{$\Delta$} \\
\hline \multicolumn{4}{|c|}{$\bar{I}$} \\
\hline \multicolumn{4}{|c|}{$\nabla$} \\
\hline \multicolumn{4}{|l|}{ Table Keylinks } \\
\hline Keyword & FragmentID & Value & LinkID \\
\hline \multicolumn{4}{|l|}{$\Delta$} \\
\hline \multicolumn{4}{|l|}{$\boldsymbol{\Delta}$} \\
\hline \multicolumn{4}{|l|}{ I } \\
\hline$\nabla$ & Table Keywords & & \\
\hline Keyword & Frequency & & \\
\hline
\end{tabular}

Figure 5 database structure

In this diagram, single arrowheads designate primary keys, double arrowheads foreign keys. The table "Data" holds the text fragments. These are stored in memo fields. In Access, ShiftF2 allows zooming in on the contents of such a field. Access can export the contents of this table to an external file.

The table "Keywords" contains each occurring keyword (once) along with its frequency. The table "Keylinks" links the tables "Data" and "Keywords". In "Keylinks", there is a row for any occurrence of a keyword in a fragment.

Finally, because InterviewStreamliner leverages the capabilities of a sophisticated database management system, its own programming code can be relatively simple. This opens the program up to users who might be inclined to join in a further development as an open source project. The fact that it is based on a relational, normalized database should make modifying and extending the program easy sailing.

InterviewStreamliner is to be found at http://www.eur.nl/fsw/soc/mtict/software/downloads/ . A manual and technical documentation are also available.

Lewins, A. and C. Silver (2007) Using Software in Qualitative Research. A Step-by-Step Guide. Los Angeles: Sage.

Lewins, A. and C. Silver (2009). Choosing a CAQDAS Package. 6th edition. CAQDAS Networking Project and Qualitative Innovations in CAQDAS Project. Retrieved from http://caqdas.soc.surrey.ac.uk/PDF/2009\%20Choosing\%20a\%20CAQDAS\%20Package.pdf, May $20^{\text {th }}, 2009$ 
Pruijt, H. (1991) "Relational databases for textual data?" in Best, H., E. Mochmann and M. Thaller (eds), Computers in the Humanities and the Social Sciences. Achievements of the 1980s. Prospects for the 1990s., München, K. G. Saur, p. 414-422.

Schipper, D. (1991), "A plea for incorporating a textual datamodel in relational databases", in Best, H., E. Mochmann and M. Thaller (eds), Computers in the Humanities and the Social Sciences. Achievements of the 1980s. Prospects for the 1990s., München, K. G. Saur, p. 423426. 